\title{
Atrial fibrillation in patients hospitalized with acute myocardial infarction: analysis of the china acute myocardial infarction (CAMI) registry
}

Yan Dai, Jingang Yang, Zhan Gao, Haiyan Xu, Yi Sun, Yuan Wu, Xiaojin Gao, Wei Li, Yang Wang, Runlin Gao, Yuejin Yang ${ }^{*}$ on behalf of the CAMl Registry study group

\begin{abstract}
Background: The incidence, clinical outcomes and antithrombotic treatment spectrum of atrial fibrillation (AF) in patients hospitalized with acute myocardial infarction (AMI) have not been well studied in Chinese population.

Methods: Twenty-six thousand five hundred ninety-two consecutive patients diagnosed with AMI were enrolled in CAMI registry from January 2013 to September 2014. After excluding 343 patients with uncertain AF status and 1,591 patients transferred out during hospitalization, 24,658 patients were finally included in this study and involved in analysis.

Results: In the CAMI registry, 740 (3.0\%) patients were recorded with AF prevalence during hospitalization. Higherrisk baseline clinical profile was observed in patients with AF. These patients were less likely to receive reperfusion/ revascularization than those without AF. The in-hospital mortality (including death and treatment withdrawal) was significantly higher in patients with AF than that of without AF $(25.2 \%$ vs. $7.2 \%$, respectively; $p<0.01)$. The case of composite of adverse events was similar, which included death, treatment withdrawal, re-infarction, heart failure or stroke $(42.1 \%$ vs. $16.0 \%, p<0.01)$. In multivariate logistic regression analysis, AF was an independent predictor for in-hospital mortality (odds ratio, 1.88; 95\% confidence interval: 1.27-2.78) and the composite of adverse events (odds ratio, $2.11 ; 95 \%$ Cl: $1.63-2.72$ ). Only $5.1 \%$ of patients with AF were treated with warfarin, and $1.7 \%$ were treated with both warfarin and dual antiplatelet therapy.
\end{abstract}

Conclusions: The analysis was based on the CAMI registry in China. The patients hospitalized for AMI who developed AF were at significantly higher risk for in-hospital mortality and other adverse events. However, the anticoagulants including warfarin have been largely underused post hospital discharge.

Trial registration: Clinical Trial Registration: Identifier: NCT01874691.

Keywords: Atrial fibrillation, Acute myocardial infarction, Hospital mortality, Anticoagulation treatment

\footnotetext{
*Correspondence: yangyj_fw@126.com

Department of Cardiology, Fuwai Hospital, National Center for Cardiovascular

Diseases, Chinese Academy of Medical Science and Peking Union Medical

College, 167 Beilishi Road, Beijing 100037, People's Republic of China
} 


\section{Background}

Atrial fibrillation (AF) is a common complication of acute myocardial infarction (AMI). The reported incidence of AF was widely ranged from 2.3 to $21.0 \%$, with an inconsistent relation to high mortality [1-12]. Although guidelines and consensus recommend a combination of warfarin and dual antiplatelet therapy (DAPT) and the duration was determined by hemorrhagic risk [13, 14], it was still complex to select an optimal antithrombotic regimen for patients with AF and AMI. Until now, this triple therapy has been largely underused in realworld clinical practice [15-17].

In China, AMI has become a major cause of emergency medical care, hospitalization and death over the past a few decades [18, 19]. The incidence, impact, and antithrombotic therapy of AF in AMI have not been correspondingly defined and demonstrated. Present analysis was aimed to study this subject with the data from China Acute Myocardial Infarction (CAMI) registry [20]. The data of patients with AMI were applied during January 2013 to September 2014. The baseline characteristics, treatment strategy, clinical data and outcomes were statistically analyzed and explored.

\section{Methods}

\section{Study population}

The design of the CAMI registry has been demonstrated in previous studies [20]. Briefly, this registry involved three levels of hospitals (representing typical Chinese governmental and administrative models) from all provinces and municipalities throughout mainland China (except for Hong Kong and Macau). Patients diagnosed with AMI were eligible for inclusion in CAMI registry, and were enrolled consecutively. Clinical data, treatments and outcomes were collected by local investigators and captured electronically with a fixed table, including a standardized set of variables and definitions, under a rigorous data quality control. A total of 108 hospitals have participated in the registry after its launch in January 2013 up to September 2014. This project was approved by the institutional review board central committee at Fuwai Hospital, National Center for Cardiovascular Diseases of China of China.

Inclusion and exclusion rules: the patients diagnosed with AMI in involved hospitals during January 2013 up to September 2014 were included. The patients were excluded if AF status was missing or they were transferred out during hospitalization. For the main analysis of in-hospital outcomes, the patients with truncated hospital stay because of outside transfer were also excluded. The presence of AF was documented by a standard 12lead electrocardiogram or electrocardiogram monitoring during hospitalization.

\section{In-hospital outcomes}

The primary outcome of this study was in-hospital mortality, which included death and treatment withdrawal (withdrawal from all medical therapy or premature hospital discharge). In China, many patients withdraw from treatment at terminal status, which could be attributed to the culture or financial affordability. Therefore, single inhospital mortality without accounting for these patients could lead to an underestimate of actual in-hospital mortality rates. Other recorded in-hospital clinical events included: re-infarction, stroke, heart failure, a composite of adverse events (the combination of death, treatment withdrawal, re-infarction, heart failure or stroke), major bleeding (including an absolute hemoglobin decrease of $3 \mathrm{~g} / \mathrm{dL}$, intracranial hemorrhage, any red blood cell transfusion or a bleeding event requiring surgical repairing), and any reported bleeding. Detailed definitions of clinical events were previously demonstrated [20].

\section{Statistical analyses}

The patient baseline characteristics, medical history, treatments, and complications were evaluated. Continuous variables are presented as median (interquartile range) and compared with Kruskal Wallis $\mathrm{H}$ test. Categorical variables were presented as counts and percentages, and were compared with chi-square or Fisher's exact tests.

Logistic regression analysis was applied to evaluate the association between AF and in-hospital mortality or the composite of adverse events. The variables included in the multivariable model were either statistically significant on univariate analysis $(p<0.05)$ or clinically critical, which were chosen by a stepwise method to minimize colinearity. Included covariates were: sex, age (>75 years), diabetes, hypertension, previous stroke, previous myocardial infarction, prior percutaneous coronary intervention (PCI)/coronary artery bypass graft (CABG), ST-segment elevation myocardial infarction (STEMI), serum creatinine, Global Registry of Acute Coronary Events (GRACE) score >140, CHA2DS2VASc score $>2$, and reperfusion therapy. Crude and adjusted odds ratios (ORs) and corresponding 95\% confidence intervals (CIs) were reported.

All comparisons were two-sided, with statistical significance defined as $p$ less than 0.05 . Statistical analysis was completed with SAS software, version 9.4.

\section{Results}

Twenty-six thousand five hundred ninety-two patients diagnosed with AMI were consecutively enrolled in CAMI registry from January 2013 to September 2014. After excluding 343 patients with uncertain AF status and 1,591 patients who were transferred out during hospitalization, 24,658 patients were finally included in this analysis. 
Among them, 740 (3.0\%) patients were recorded with AF prevalence during hospitalization (Fig. 1).

Baseline characteristics of patients were shown (Table 1). Compared with patients without AF, the age of patients with AF were higher (mean age: 73 vs. 63 years, $p<0.01$ ), more likely to be women ( $35.1 \%$ vs. $25.5 \%, p<0.01)$ and with more comorbidities such as hypertension $(59.3 \%$ vs. $51.2 \%, p<0.01)$, heart failure (7.7\% vs. $2.4 \%, p<0.01)$ and stroke $(17.8 \%$ vs. $9.2 \%, p<0.01)$.Patients with AF were less frequently presented with STEMI than those without AF ( $65.7 \%$ vs. $76.0 \%, p<0.01$ ), and had worse left ventricular function. The proportions of CHA2DS2-VASc $\geq 2(66.1 \%$ vs. $45.5 \%, p<0.01)$ and HAS-BLED $\geq 3$ scores $(21.4 \%$ vs.10.8\%, $p<0.01)$ were significantly higher in patients with AF, as well as the GRACE $(161$ vs.129, $p<0.01)$ and Thrombolysis in Myocardial Infarction (TIMI) scores (6 vs.4, $p<0.01$ ). Patients with AF received reperfusion/ revascularization during hospitalization at a lower rate than those without AF $(35.9 \%$ vs. $48.3 \%$, respectively, $p<0.01)$, as the case for $\operatorname{PCI}(29.7 \%$ vs. $40.5 \%$, respectively, $p<0.01$ ).

The antithrombotic treatment regimens in AMI patients with and without AF were summarized (Table 2). During hospitalization, $78.0 \%$ of patients with AF received DAPT, less than the rate of $86.3 \%$ in patients without $\mathrm{AF}(p<0.01)$. However, the rates of anticoagulants treatment including unfractionated heparin (UFH), low molecular weight heparin (LMWH) and fondaparinux both groups were similar. A majority of patients received DAPT (86.1\%) and LMWH (84.2\%). Only $3.5 \%$ of patients with AF received warfarin, which was nonetheless higher than the rate of $1.4 \%$ in patients without $\mathrm{AF}(p<0.01)$.

At hospital discharge, $76.2 \%$ of patients with AF received DAPT, which was lower than the rate of $86.1 \%$ in patients without AF $(p<0.01)$. However, only $5.1 \%$ of patients with AF were discharged on warfarin, and the proportion of warfarin in combination with DAPT was as low as $1.7 \%$. In addition, no new direct oral anticoagulants (dabigatran, rivaroxaban, and apixaban) were applied in any patient.

The in-hospital outcomes were summarized (Table 3). Rate of in-hospital mortality (death or treatment withdrawal) was significantly higher in patients with $\mathrm{AF}$ $(25.2 \%)$ than that of without $\operatorname{AF}(7.2 \%)(p<0.01)$. The rate of composite of adverse events (death, treatment withdrawal, re-infarction, heart failure or stroke) was also significantly higher in AF group (42.1\% vs. $16.0 \%, p$ $<0.01$ ), which was also the case for individual component of the composite. In multivariate logistic regression analysis, AF was an independent predictor for both inhospital mortality (odds ratio: 1.88, 95\%CI: 1.27-2.78) and the composite of adverse events (2.11, 95\% CI: $1.63-2.72$, respectively) (Figs. 2 and 3). The rate of major bleeding was $1.7 \%$ in patients with $\mathrm{AF}$, numerically higher than the rate of $0.9 \%$ for patients without $\mathrm{AF}$ $(p=0.65)$.

\section{Discussion}

CAMI registry was the largest nationwide observational study to date for hospitalized patients with AMI throughout China. The major findings of present analysis were: 1 ) the overall incidence of AF was 3.0\% in Chinese patients with AMI during hospitalization; 2) the risk of baseline profile was higher in patients with AF than patients without AF; 3) patients who developed AF were at a 1.88-fold higher risk of in-hospital mortality than patients without AF; and 4) although the majority of AMI patients complicated with $\mathrm{AF}$ received anticoagulation and antiplatelet

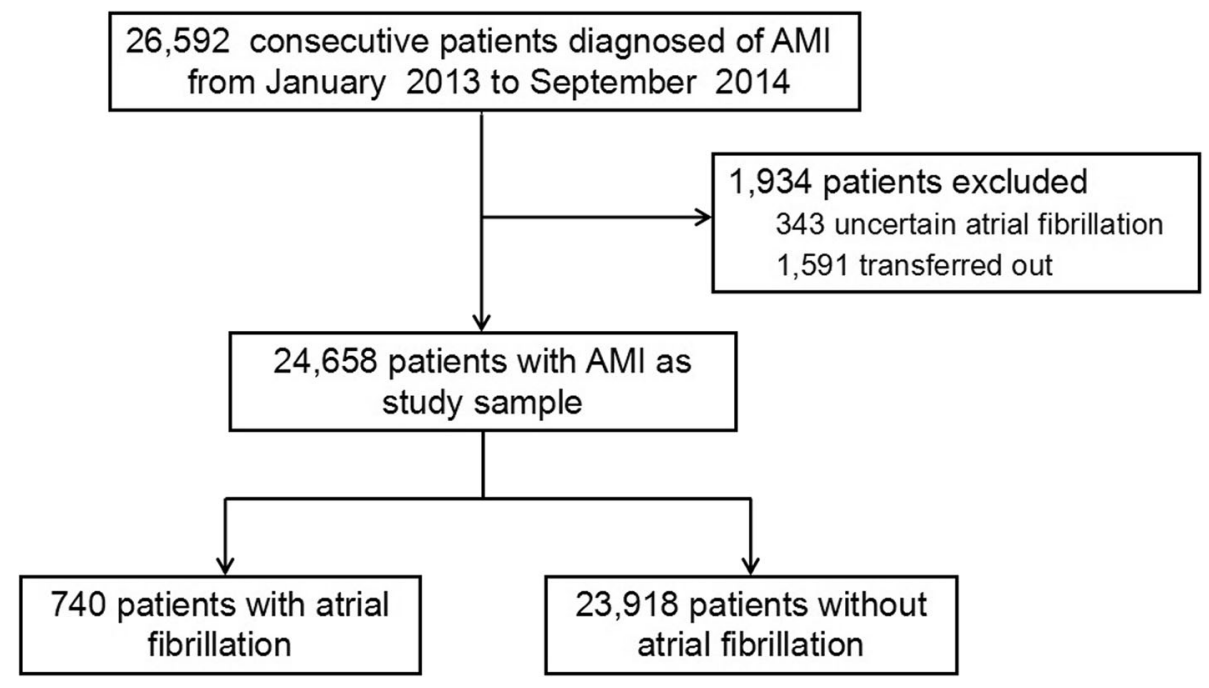

Fig. 1 Population flow chart. AMI = acute myocardial infarction 
Table 1 Baseline characteristics

\begin{tabular}{lllll}
\hline $\begin{array}{l}\text { Overall } \\
\text { population } \\
(n=24658)\end{array}$ & AF & No AF & $P$ value \\
$(n=740)$ & $(n=23918)$ & \\
\end{tabular}

Demographics

$\begin{array}{lllll}\text { Age(years) } & 63(53-72) & 73(65- & 63(53-72) & <0.01 \\ & 79) & & \\ \text { Men } & 74.2 & 64.9 & 74.5 & <0.01\end{array}$

Medical history

Previous angina

pectoris

PreviousMl

28.2

64.9

74.5

$<0.0$

PreviousPCI/CABG

Previous heart failure

Previous stroke

Previous peripheral

arterial disease

Chronic renal failure $\quad 1.4$

Cardiovascular risk factors

$\begin{array}{lllll}\text { Hypertension } & 51.5 & 59.3 & 51.2 & <0.01 \\ \text { Hyperlipidemia } & 8.0 & 6.3 & 8.1 & 0.10 \\ \text { Diabetes mellitus } & 20.0 & 18.8 & 20.0 & 0.44 \\ \begin{array}{l}\text { Family history of } \\ \text { premature CAD }\end{array} & 4.0 & 3.0 & 4.0 & 0.12 \\ \begin{array}{l}\text { Current smoker } \\ \text { S }\end{array} & 54.7 & 44.7 & 55.0 & <0.01\end{array}$

Clinical characteristics

$\begin{array}{lllll}\text { STEMI } & 75.7 & 65.7 & 76.0 & <0.01 \\ \text { LVEF(\%) } & 55(47-60) & 50(41-59) & 55(47-60) & <0.01 \\ \text { Killip classification III-IV } & 9.2 & 24.2 & 8.7 & <0.01 \\ \text { CHA2DS2-VASC } \geq 2 & 46.1 & 66.1 & 45.5 & <0.01 \\ \text { HAS-BLED } \geq 3 & 11.1 & 21.4 & 10.8 & <0.01 \\ \text { GRACE Score } & 129(112- & 161(133- & 129(112- & <0.01\end{array}$

TIMI Score

$\begin{array}{lllll}\text { STEMI } & 4(2-6) & 6(4-8.5) & 4(2-6) & <0.01 \\ \text { NSTEMI } & 2(2-3) & 2(2-3) & 2(1-3) & <0.01\end{array}$

Treatments

\begin{tabular}{lllll} 
Reperfusion Therapy & 48.0 & 35.9 & 48.3 & $<0.01$ \\
PCI & 40.2 & 29.7 & 40.5 & $<0.01$ \\
Fibrinolysis & 7.8 & 6.2 & 7.8 & $<0.01$ \\
ACE/ARB & 59.7 & 54.8 & 59.9 & 0.02 \\
B-blockers & 69.9 & 59.9 & 70.2 & $<0.01$ \\
Anti-arrhythmia drugs & 9.8 & 45.4 & 8,7 & $<0.001$ \\
\hline
\end{tabular}

Data are presented as median (IQR) or \%

$A F$ atrial fibrillation, $M I$ myocardial infarction, $P C l$ percutaneous coronary intervention, $C A B G$ coronary artery bypass graft, $C A D$ coronary artery disease, $\angle V E F$ left ventricular ejection fraction, GRACE global registry of acute coronary events, TIMI thrombolysis in myocardial infarction, STEMI ST-segment elevation myocardial infarction, NSTEMI non-ST-elevation myocardial infarction, ACEI angiotensin-converting enzyme, $A R B$ angiotensin receptor blocker
Table 2 Antithrombotic treatment strategy in-hospital and at hospital discharge

\begin{tabular}{lllll}
\hline & $\begin{array}{l}\text { Overall population } \\
(n=24658)\end{array}$ & $\begin{array}{l}\text { AF } \\
(n=740)\end{array}$ & $\begin{array}{l}\text { No AF } \\
(n=23918)\end{array}$ & $P$ value \\
\hline In-hospital $^{a}$ & & & & \\
DAPT & 86.1 & 78.0 & 86.3 & $<0.01$ \\
UFH & 5.9 & 5.2 & 5.9 & 0.43 \\
LMWH & 84.2 & 84.9 & 84.1 & 0.59 \\
Fondaparinux & 3.8 & 2.9 & 3.9 & 0.16 \\
Warfarin & 1.4 & 3.5 & 1.4 & $<0.01$ \\
At hospital discharge & & & & $<0.01$ \\
DATP & 85.9 & 76.2 & 86.1 & $<0.01$ \\
Warfarin & 1.9 & 5.1 & 1.4 & 0.02 \\
Warfarin alone & 0.3 & 1.0 & 0.3 & $<0.01$ \\
Warfarin + single & 0.9 & 2.4 & 0.7 & $<0.01$ \\
antiplatelet drug & & 1.7 & 0.5 & \\
Warfarin + DAPT & 0.7 & & &
\end{tabular}

$A F$ atrial fibrillation, DAPT dual antiplatelet therapy, UFH unfractionated heparin, $L M W H$ low molecular weight heparin

${ }^{a}$ Not including anticoagulants administered in catheterization laboratory

therapy during hospitalization, only $5.1 \%$ of them were discharged on warfarin, and $1.7 \%$ were discharged on both warfarin and DAPT.

In this nationally representative study, it firstly defined an AF incidence of $3.0 \%$ in contemporarily treated AMI patients in China. It was much lower compared to the reported data in other countries, ranging from 2.3 to $21 \%[1-12]$. It may be resulted from some possible

Table 3 In-hospital events

\begin{tabular}{|c|c|c|c|c|}
\hline & $\begin{array}{l}\text { Overall population } \\
(n=24658)\end{array}$ & $\begin{array}{l}\text { AF } \\
(n=740)\end{array}$ & $\begin{array}{l}\text { No AF } \\
(n=23918)\end{array}$ & $P$ value \\
\hline Death & 4.4 & 14.0 & 4.1 & $<0.01$ \\
\hline $\begin{array}{l}\text { Treatment } \\
\text { withdrawal }\end{array}$ & 3.3 & 11.2 & 3.1 & $<0.01$ \\
\hline $\begin{array}{l}\text { Death + Treatment } \\
\text { withdrawal }\end{array}$ & 7.7 & 25.2 & 7.2 & $<0.01$ \\
\hline Re-infarction & 0.6 & 1.4 & 0.6 & 0.02 \\
\hline Stroke & 0.8 & 1.9 & 0.7 & $<0.01$ \\
\hline Ischemic & 0.6 & 1.4 & 0.5 & \\
\hline Hemorrhagic & 0.08 & 0.13 & 0.07 & \\
\hline Unknown & 0.11 & 0.4 & 0.09 & \\
\hline Heart failure & 16.7 & 42.1 & 16.0 & $<0.01$ \\
\hline $\begin{array}{l}\text { Composite of } \\
\text { adverse events }^{\text {a }}\end{array}$ & 19.2 & 47.5 & 18.4 & $<0.01$ \\
\hline Major bleeding ${ }^{b}$ & 0.9 & 1.7 & 0.9 & 0.65 \\
\hline Any bleeding & 1.8 & 2.7 & 1.8 & 0.09 \\
\hline
\end{tabular}

${ }^{\mathrm{a} C o m p o s i t e}$ of adverse events: death, treatment withdrawal, re-infarction, heart failure or stroke

${ }^{\mathrm{b}}$ Major bleeding was defined as an absolute hemoglobin decrease of $3 \mathrm{~g} / \mathrm{dL}$, intracranial hemorrhage, any red blood cell transfusion or a bleeding event requiring surgical repair 


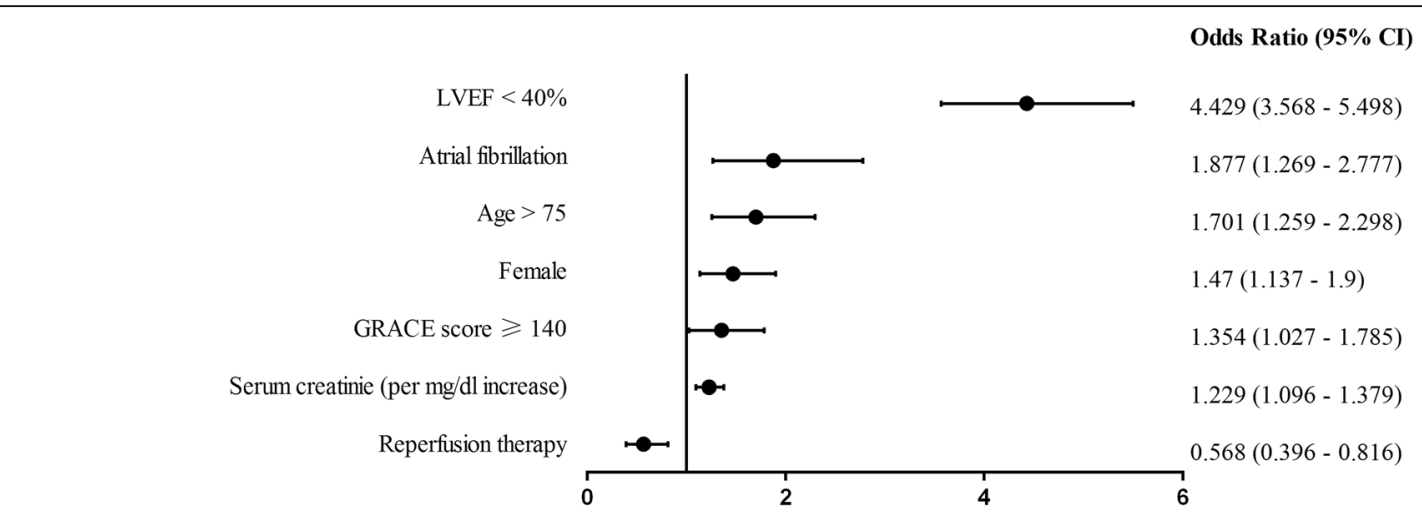

Fig. 2 Multivariable analysis of predictors of in-hospital mortality*. * In-hospital mortality included in-hospital death and treatment withdrawal. $\mathrm{LVEF}=$ left ventricular ejection fraction; GRACE $=$ Global Registry of Acute Coronary Events

explanations. First, age was the most commonly reported risk factor for AMI complicated with AF [21, 22], and the low rate of AF in CAMI patients may be associated with an overall lower mean age of 63 years in samples. Second, $48.0 \%$ of overall patients in CAMI received reperfusion therapy $(42.2 \% \mathrm{PCI})$. In previous studies, widespread use of reperfusion therapy, especially PCI, was associated with a notable decline of AF incidence $[11,23]$. Third, the majority of patients in CAMI were treated with angiotensin-converting enzymes/angiotensin receptor inhibitors or $\beta$-blockers, and trials evaluating the effects of these drugs in patients with AMI have reported lower incidence rates of AF, although mainly making effects on late developing AF [24, 25]. Fourth, ethnic differences may also account for the wide incidence range of AMI complicated AF among different countries. A recently published study reported a low AF incidence of $2.7 \%$ in Arabian Gulf patients with acute coronary syndrome (ACS) [4].
Consistent with previous studies [1-12], in CAMI registry, higher-risk baseline clinical characteristics could be observed in AMI patients complicated with AF during hospitalization, including older age, a greater cardiovascular risk factor burden, more comorbidities, poorer left ventricular function, and higher clinical risk scores. The present study also documented that AMI patients with AF were less likely to receive reperfusion/revascularization than those without AF. For the patients with older age and more comorbidities, more conservative management approach would be selected by the physicians [26].

It indicated that $\mathrm{AF}$ increased the risk of morbidity and mortality in patients with ACS, and that this association would be mediated to a greater or lesser extent by various comorbidities [1]. However, because of differences in study design and data availability, including study population, AF classification, sample size, and follow-up duration, the association between AF development in ACS and increased in-hospital mortality

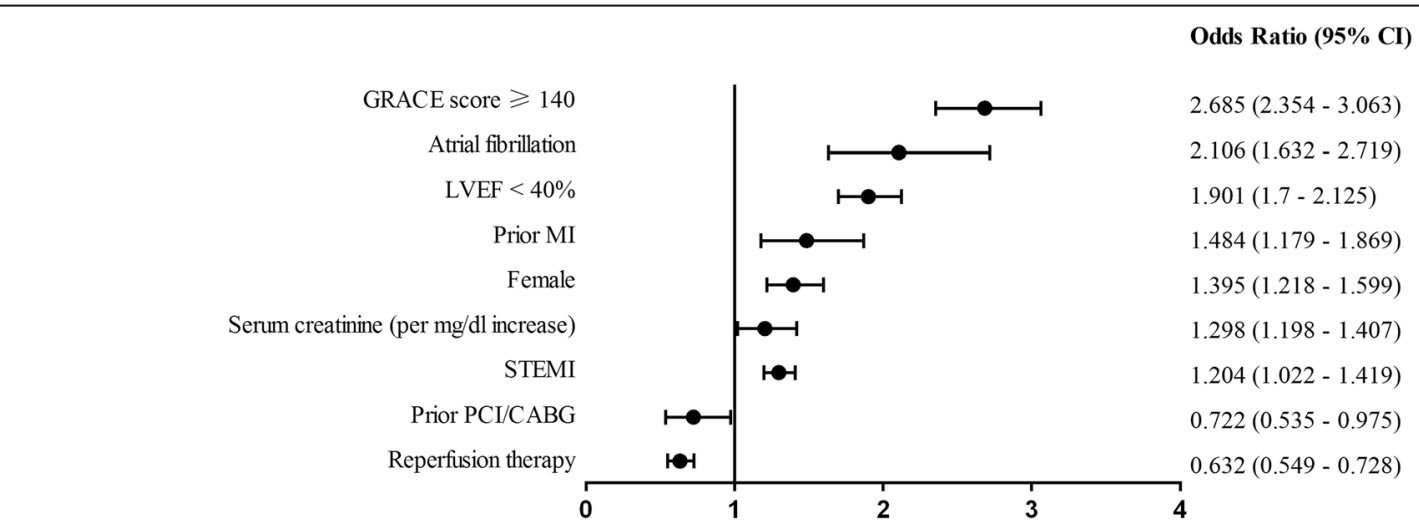

Fig. 3 Multivariable analysis of predictors of the composite of adverse events*. *The composite of adverse events included in-hospital death, treatment withdrawal, re-infarction, heart failure or stroke. GRACE = Global Registry of Acute Coronary Events; LVEF = left ventricular ejection fraction; MI = myocardial infarction; STEMI = ST-segment elevation myocardial infarction; $\mathrm{PCl}=$ percutaneous coronary intervention; $C A B G=$ coronary artery bypass graft 
remained to be controversial. Some variables were reported to be independently associated with AF [2-9], while others reported no association [10-12]. In present analysis, the data was obtained from the CAMI registry, which was a large-scale, national and contemporary registry project for AMI patients in China [20]. The inhospital mortality was significantly higher in patients with $\mathrm{AF}$ in unadjusted analysis. In addition, AF was also an independent multivariate risk factor of mortality after adjusting for possible confounders, although to an attenuated extent. With the consistency of findings, the association was further underscored in unadjusted and adjusted analyses.

The risk of bleeding may be increased by the anticoagulants treatment combined with DAPT therapy for stroke prevention in ACS patients with AF $[27,28]$. However, current guidelines and consensus recommend a combination of warfarin and DAPT (triple therapy), with adjustment of duration according to hemorrhagic risk $[13,14]$. Nonetheless, in previous studies, it documented that this triple therapy was largely underused, with a frequency ranged from 5.7 to $15.6 \%$ [15-17]. In the CAMI national registry, only $5.1 \%$ of AMI patients with AF were discharged on warfarin, and the proportion of warfarin in combination with DAPT was even as low as $1.7 \%$. The latter striking gap in China might be secondary to many factors: the uncertainty about the benefits of intense anticoagulation in these high risk patients, inadequate provider knowledge, structural inadequacies of healthcare delivery systems, and/or concern about potential violence and litigation from patients or their families due to complications associated with treatment [29-31]. In addition, although new direct oral anticoagulants (dabigatran, rivaroxaban, and apixaban) have been approved for stroke prevention in non-valvular AF patients [13], the CAMI registry indicated that these new anticoagulants have not been applied yet in AMI patients with AF in China.

CAMI registry was compared with REAL (REgistro regionale AngiopLastiche dell'Emilia-Romagna) registry. REAL registry was a multi-center, large scale, prospective study [32-35]. It aimed to collect the clinical data of coronary interventional cases from 4 million residents in Emilia- Romagna. 13 hospitals participated in this registry. The data could be retrieved in database. Many studies were performed based on this database [36]. Similar to REAL registry, CAMI has collected information of patients with acute myocardial infarction (AMI), including the clinical data, treatment, efficacy and prognosis. It aimed to improve the overall treatment efficacy of AMI in China. However, CAMI has only focused the patients from China. Different from REAL registry, CAMI has involved 108 hospitals in Chinese mainland and the hospitals differed in levels in CAMI registry. In addition, the population base was larger in CAMI registry in China.
Finally, the involved cases were updated (since 2013). The study based on CAMI would be promising in improving the treatment efficacy of AMI in China.

\section{Strengths and limitations}

CAMI is the largest national registry of patients with AMI. The population in the registry was representative of different regions, economic strata and access to medical resources in China. Therefore, the CAMI registry can adequately reflect the current performance and status of healthcare system in China. The data was valuable, specific and updated, which was based on a larger population base. Nevertheless, our study has several limitations. First, CAMI was subject to inherent limitations and potential biases, including the collection of nonrandomized data, missing or incomplete information, and potential confounding by drug indications or other unmeasured covariates which must be considered in results interpretation. Second, our database did not allow the identification of timing, type and duration of AF (paroxysmal, persistent or permanent), as well as the AF history, which may make effects on the prognosis prediction of the patients. Third, we do not include the follow-up data after hospital discharge, including both the mortality and other clinical events.

\section{Conclusions}

In China, AF development in patients with AMI was associated with significantly higher in-hospital mortality, and the anticoagulants including warfarin were largely underused during hospitalization and after hospital discharge. The conclusion on prediction and treatment may be instructional towards both clinical practice and further relevant studies.

\section{Abbreviations \\ AF: Atrial fibrillation; AMI: Acute myocardial infarction; DAPT: Dual antiplatelet therapy; CAMI: China acute myocardial infarction; PCI: Percutaneous coronary intervention; CABG: Coronary artery bypass graft; STEMI: ST-segment elevation myocardial infarction; GRACE: Global registry of acute coronary events; OR: Odds ratio; Cl: Confidence interval; TIMI: Thrombolysis in myocardial infarction; UFH: Unfractionated heparin; LMWH: Low molecular weight heparin; ACS: Acute coronary syndrome}

\section{Acknowledgments}

The authors expressed their gratitude to all investigators and coordinators who participated in CAMI registry. Further information about the CAMI project, along with a list of participants, is available at http://www.CAMIRegistry.org.

\section{Funding}

The project was financial supported by one of the National Twelfth Five-year Science and Technology Support Projects by the Ministry of Science and Technology of China (Grant No. 2011BAl11B02).

\section{Availability of data and materials}

The data supporting our findings are available at http://www.CAMIRegistry.org. However, the data is not publicly available and can only be provided in the Chinese language so far. The corresponding author Yuejin Yang (yangyj_fw@126.com) can be contacted in order to request permission to view the data. 


\section{Authors' contributions}

In this study, YD, JY, ZG, RG and YY were involved in the design and analysis of data, drafting and revising of the manuscript and final approval of the submitted manuscript; HX, YS, YW, XG, WL, and YW were involved in the analysis of data, revising of the manuscript critically for important intellectual content and final approval of the manuscript submitted. All authors read and approved the final manuscript

\section{Competing interests}

The authors declare that they have no competing interests.

\section{Consent for publication}

Not applicable.

\section{Ethics approval and consent to participate}

The CAMI registry was approved by the institutional review board central committee at Fuwai Hospital, National Center for Cardiovascular Diseases of China of China.

\section{Received: 21 July 2016 Accepted: 13 December 2016} Published online: 04 January 2017

\section{References}

1. Schmitt J, Duray G, Gersh BJ, Hohnloser SH. Atrial fibrillation in acute myocardial infarction: a systematic review of the incidence, clinical features and prognostic implications. Eur Heart J. 2009;30(9):1038-45.

2. Lopes RD, Pieper KS, Horton JR, Al-Khatib SM, Newby LK, Mehta RH, et al. Short- and long-term outcomes following atrial fibrillation in patients with acute coronary syndromes with or without ST-segment elevation. Heart. 2008:94(7):867-73.

3. Gonzalez-Pacheco H, Marquez MF, Arias-Mendoza A, Alvarez-Sangabriel A, Eid-Lidt G, Gonzalez-Hermosillo A, et al. Clinical features and in-hospital mortality associated with different types of atrial fibrillation in patients with acute coronary syndrome with and without ST elevation. J Cardiol. 2015; 66(2):148-54.

4. Hersi A, Alhabib KF, Alsheikh-Ali AA, Sulaiman K, Alfaleh HF, Alsaif S, et al. Prognostic significance of prevalent and incident atrial fibrillation among patients hospitalized with acute coronary syndrome: findings from the Gulf RACE-2 Registry. Angiology. 2012;63(6):466-71.

5. Lau DH, Huynh LT, Chew DP, Astley CM, Soman A, Sanders P. Prognostic impact of types of atrial fibrillation in acute coronary syndromes. Am J Cardiol. 2009;104(10):1317-23.

6. Jabre P, Roger VL, Murad MH, Chamberlain AM, Prokop L, Adnet F, et al. Mortality associated with atrial fibrillation in patients with myocardial infarction: a systematic review and meta-analysis. Circulation. 2011;123(15): 1587-93.

7. Podolecki T, Lenarczyk R, Kowalczyk J, Kurek T, Boidol J, Chodor P, et al. Effect of type of atrial fibrillation on prognosis in acute myocardial infarction treated invasively. Am J Cardiol. 2012;109(12):1689-93.

8. Rene AG, Genereux P, Ezekowitz M, Kirtane AJ, Xu K, Mehran R, et al. Impact of atrial fibrillation in patients with ST-elevation myocardial infarction treated with percutaneous coronary intervention (from the HORIZONS-AMI [Harmonizing Outcomes With Revascularization and Stents in Acute Myocardial Infarction] trial). Am J Cardiol. 2014;113(2):236-42.

9. McManus DD, Huang W, Domakonda KV, Ward J, Saczysnki JS, Gore JM, et al. Trends in atrial fibrillation in patients hospitalized with an acute coronary syndrome. Am J Med. 2012;125(11):1076-84.

10. Eldar M, Canetti M, Rotstein Z, Boyko V, Gottlieb S, Kaplinsky E, et al. Significance of paroxysmal atrial fibrillation complicating acute myocardial infarction in the thrombolytic era. SPRINT Thrombolytic Surv Groups Circ. 1998:97(10):965-70.

11. Kinjo K, Sato H, Ohnishi Y, Hishida E, Nakatani D, Mizuno H, et al. Prognostic significance of atrial fibrillation/atrial flutter in patients with acute myocardial infarction treated with percutaneous coronary intervention. Am J Cardiol. 2003:92(10):1150-4.

12. Asanin M, Perunicic J, Mrdovic I, Matic M, Vujisic-Tesic B, Arandjelovic A, et al. Prognostic significance of new atrial fibrillation and its relation to heart failure following acute myocardial infarction. Eur J Heart Fail. 2005;7(4): 671-6.

13. Camm AJ, Lip GY, De Caterina R, Savelieva I, Atar D, Hohnloser SH, et al. 2012 focused update of the ESC guidelines for the management of atrial fibrillation: an update of the 2010 ESC guidelines for the management of atrial fibrillation. Developed with the special contribution of the european heart rhythm association. Eur Heart J. 2012;33(21):2719-47.

14. Faxon DP, Eikelboom JW, Berger PB, Holmes DR, Bhatt DL, Moliterno DJ, et al. Consensus document: antithrombotic therapy in patients with atrial fibrillation undergoing coronary stenting. North-American perspect Thromb Haemost. 2011;106(4):572-84.

15. Chamberlain AM, Gersh BJ, Mills RM, Klaskala W, Alonso A, Weston SA, et al. Antithrombotic strategies and outcomes in acute coronary syndrome with atrial fibrillation. Am J Cardiol. 2015;115(8):1042-8.

16. Maier B, Hegenbarth C, Theres $H$, Schoeller R, Schuehlen H, Behrens S. Antithrombotic therapy in patients with atrial fibrillation and acute coronary syndrome in the real world: data from the berlin AFibACS registry. Cardiol J. 2014;21(5):465-73.

17. Lopes RD, Li L, Granger CB, Wang TY, Foody JM, Funk M, et al. Atrial fibrillation and acute myocardial infarction: antithrombotic therapy and outcomes. Am J Med. 2012;125(9):897-905.

18. Chen ZM, Jiang LX, Chen YP, Xie JX, Pan HC, Peto R, et al. Addition of clopidogrel to aspirin in 45,852 patients with acute myocardial infarction: randomised placebo-controlled trial. Lancet. 2005;366(9497):1607-21.

19. Gao R, Patel A, Gao W, Hu D, Huang D, Kong L, et al. Prospective observational study of acute coronary syndromes in China: practice patterns and outcomes. Heart. 2008;94(5):554-60.

20. Xu H, Li W, Yang J, Wiviott SD, Sabatine MS, Peterson ED, et al. The China Acute Myocardial Infarction (CAMI) Registry: A national long-term registryresearch-education integrated platform for exploring acute myocardial infarction in China. Am Heart J. 2016;175(5):193-201.e3

21. Rathore SS, Berger AK, Weinfurt KP, Schulman KA, Oetgen WJ, Gersh BJ, et al. Acute myocardial infarction complicated by atrial fibrillation in the elderly: prevalence and outcomes. Circulation. 2000;101(9):969-74.

22. Fang MC, Chen J, Rich MW. Atrial fibrillation in the elderly. Am J Med. 2007; 120(6):481-7.

23. Goldberg RJ, Yarzebski J, Lessard D, Wu J, Gore JM. Recent trends in the incidence rates of and death rates from atrial fibrillation complicating initial acute myocardial infarction: a community-wide perspective. Am Heart J. 2002;143(3):519-27.

24. Anand K, Mooss AN, Hee TT, Mohiuddin SM. Meta-analysis inhibition of renin-angiotensin system prevents new-onset atrial fibrillation. Am Heart J. 2006;152(2):217-22.

25. Ehrlich JR, Hohnloser SH, Nattel S. Role of angiotensin system and effects of its inhibition in atrial fibrillation: clinical and experimental evidence. Eur Heart J. 2006:27(5):512-8.

26. Fox KA, Anderson Jr FA, Dabbous OH, Steg PG, Lopez-Sendon J, Van de Werf $F$, et al. Intervention in acute coronary syndromes: do patients undergo intervention on the basis of their risk characteristics? The Global Registry of Acute Coronary Events (GRACE). Heart. 2007;93(2): 177-82.

27. Lamberts M, Gislason GH, Olesen JB, Kristensen SL, Schjerning Olsen AM Mikkelsen A, et al. Oral anticoagulation and antiplatelets in atrial fibrillation patients after myocardial infarction and coronary intervention. J Am Coll Cardiol. 2013;62(11):981-9.

28. Lamberts M, Olesen JB, Ruwald MH, Hansen CM, Karasoy D, Kristensen SL, et al. Bleeding after initiation of multiple antithrombotic drugs, including triple therapy, in atrial fibrillation patients following myocardial infarction and coronary intervention: a nationwide cohort study. Circulation. 2012; 126(10):1185-93.

29. Du X, Gao R, Turnbull F, Wu Y, Rong Y, Lo S, et al. Hospital quality improvement initiative for patients with acute coronary syndromes in China: a cluster randomized, controlled trial. Circ Cardiovasc Qual Outcomes. 2014;7(2):217-26.

30. Ranasinghe I, Rong Y, Du X, Wang Y, Gao R, Patel A, et al. System barriers to the evidence-based care of acute coronary syndrome patients in China: qualitative analysis. Circ Cardiovasc Qual Outcomes. 2014;7(2):209-16.

31. Lancet T. Chinese doctors are under threat. Lancet. 2010;376(9742):657.

32. Campo G, Guastaroba P, Marzocchi A, Santarelli A, Varani E, Vignali L, et al. Impact of copd on long-term outcome after st-segment elevation myocardial infarction receiving primary percutaneous coronary intervention. Chest. 2013;144(3):750-7.

33. Campo G, Saia F, Guastaroba P, Marchesini J, Varani E, Manari A, et al. Prognostic impact of hospital readmissions after primary percutaneous coronary intervention. Arch Intern Med. 2011;171(21):1948-9. 
34. Campo G, Saia F, Percoco G, et al. Long-term outcome after drug eluting stenting in patients with ST-segment elevation myocardial infarction: data from the REAL registry. Int J Cardiol. 2010;140(2):154-60.

35. Percoco G, Manari A, Guastaroba P, et al. Safety and long-term efficacy of sirolimus eluting stent in ST-elevation acute myocardial infarction: the REAL (Registro REgionale AngiopLastiche Emilia-Romagna) registry. Cardiovasc Drugs Ther. 2006;20(1):63-8.

36. Valgimigli M, Saia F, Guastaroba P, et al. Transradial versus transfemoral intervention for acute myocardial infarction : a propensity score-adjusted and -matched analysis from the REAL (REgistro regionale AngiopLastiche dell'Emilia-romagna) multicenter registry. J Am Coll Cardiol Intv. 2012;5(1): 23-35.

Submit your next manuscript to BioMed Central and we will help you at every step:

- We accept pre-submission inquiries

- Our selector tool helps you to find the most relevant journal

- We provide round the clock customer support

- Convenient online submission

- Thorough peer review

- Inclusion in PubMed and all major indexing services

- Maximum visibility for your research

Submit your manuscript at www.biomedcentral.com/submit
Biomed Central 